\title{
Axial Flow PAF Accident Analysis and Solutions of Thermal Power Unit
}

\author{
Li Jun \\ Grid Technology Center \\ State Grid Shandong Electric Power Research Institute \\ Jinan, China \\ lijun_sdu@hotmail.com
}

\author{
Li Weiwei \\ Network Center \\ Shandong University of Arts \\ Jinan, China \\ liweiwei@sdca.edu.cn
}

\begin{abstract}
Surge is a frequent problem in large axial flow adjustable suction fan. Cause of surge as well as hazard to unit and production was introduced. Pointed out that thermal power after the denitration system transformation, due to changes in the resistance of air and gas systems, so that the whole system aerodynamic field changes, it can easily cause primary air fan (PAF) surge accidents. By analyzing the PAF surge accident of the typical thermal unit, the anti-surge control scheme is formulated.
\end{abstract}

Keywords-surge; primary air fan; stall line; axial flow; thermal power unit

\section{INTRODUCTION}

On 12 November 2014, China-U.S. Joint Statement on Climate Change pointed out that in light of the overwhelming scientific consensus on climate change and its worsening impacts, and the related issue of air pollution from burning fossil fuels, China and the United States recognize the urgent need for action to meet these twin challenges. Both sides reaffirm their commitment to contribute significantly to successful 2015 global efforts to meet this challenge.

As the major consumer of coal resource, China's thermal power plant emission management is becoming more and more strictly. In recent years, thermal power unit generally carried out denitration transformation, mainly taken low nitrogen burners transformation and increase SCR denitration apparatus for removing nitrogen oxides in the flue gas. SCR denitration technology use NH3 as a reducing agent injected into the flue gas, the reducing agent and the flue gas NOx reduction reaction occurs to generate harmless $\mathrm{N}_{2}$ and $\mathrm{H}_{2} \mathrm{O}$, so as to achieve the purpose of removing nitrogen oxides. SCR's denitration efficiency can reach more than $90 \%$, significantly reduce NOx emissions. Flue gas emissions can meet the strict environmental protection standards, but SCR will produce great influence to the boiler safe and economic operation. SCR makes flue gas resistance increased about $500 \mathrm{~Pa}$, it lead to induced draft fan power consumption to increase, change aerodynamic field, directly affect the safety of the boiler and stable operation. At the same time, adjusting air delivery by changing the blade angle in operation, adjustable-blade axial flow fans have favorable adjusting performance and are widely used in large boilers. The increase of flue gas resistance is easily to lead to PAF surge accidents.

\section{PRIMARY AIR AND SURGE}

The work process of primary air fan as shown in Fig.1, boiler air and gas system continuously provide the required air quantity for boiler fuel burning, distribute air to the location according to the requirement of the combustion air flow, and make the air containing dust combustion generated after the heating surface and flue gas purification device, finally discharge to the atmosphere.

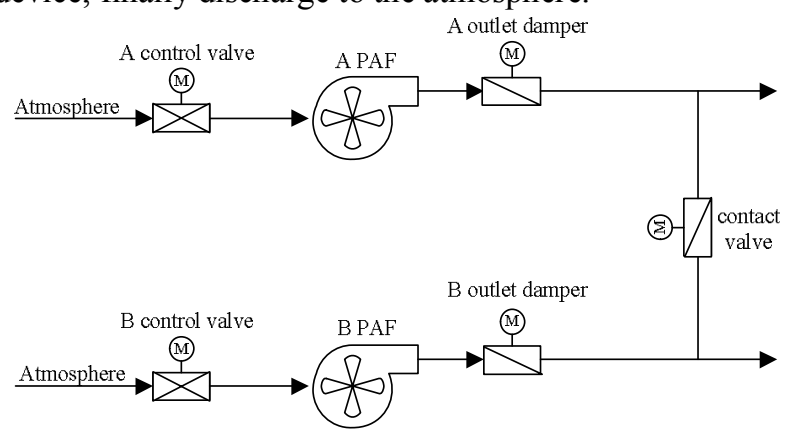

Figure 1. The work process of primary air

\section{A. Primary air}

Primary air is used to transport and dry pulverized coal and supply the air which required for the initial fuel to burn. Air through the filter, muffler vertically into two axial flow fans, by the PAF put pressure, is divided into two routes. One is put into the cold PAF pipe, another heated by primary air sector of air preheater is sent into hot PAF pipe, hot and cold air are mixed before the mill. In the hot and cold PAF wind outlet is equipped with the damper and electric damper to control the air flow of hot and cold wind, ensure that the total air flow requirements and mill outlet temperature at $70^{\circ} \mathrm{C}$. Qualified pulverized coal is sent to the furnace by the primary air through pulverized coal pipe.

The PAF flow mainly depends on the amount of air that combustion system required and preheater leakage flow. The pressure head of primary air mainly depends on the pulverized coal flow resistance and air duct, preheater, damper, flow resistance of coal mill. Its head is pink with boiler demand change and can be changed by adjusting the angle of the rotor to change the air flow, to maintain primary air pipe pressure, to adapt to different load. 


\section{B. Working principle of axial flow fan}

Fluid along the axial flow blades channel, when under the drive of motor rotating impeller rotating blades to the fluid flow around a along the axial thrust. Blade in the fluid flow around the blade, and according to the principle of fluid mechanics, fluid of blade has a lift, at the same time by the principle of action and reaction are equal, leaf also function to a fluid with equal force in the opposite direction to lift, namely thrust[1,2]. This blade thrust on fluid power, increase the energy of the fluid along the axial exhaust. Blade is formed namely continuous rotation of axial fan work continuously.

Imagine a long cylinder, air flow from left to right as a parallel flow, regardless of the gas viscosity (i.e., the gas flow resistance), then the gas will be uniform consists of flow around the cylinder. Airflow velocity and pressure distribution on the cylinder is completely symmetrical[3]. The total force of fluid of cylinder is zero, as shown in Fig.2. This fluid is called advection flow around the cylinder.

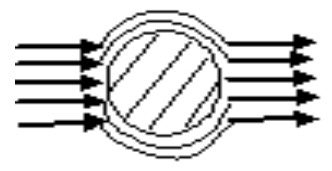

Figure 2. Parallel flow

And cylinder to rotate clockwise motion, the surrounding gas cylinder rotate together, also produce circulation movement. At this time on the cylinder, the velocity and pressure distribution is completely symmetrical. The total force of fluid of cylinder is zero, as shown in Fig.3. This movement is circulation.

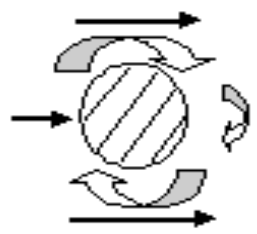

Figure 3. Circulation

If fluid makes parallel motion, the cylinder to rotate clockwise, the superposition of two flows together is the upper cylinder horizontal flow and circulation in the same direction, flow speed. Cylinder bottom advection and circulation in the opposite direction, slows down. According to the principle of energy equation, the total energy of the lower part of the upper cylinder and the cylinder are equal, and the cylinder upside momentum is big, pressure is small, the lower kinetic energy is small, high pressure. So fluid produces a bottom-up pressure difference to the cylinder, the pressure difference is the lift.

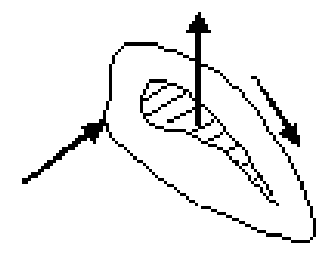

Figure 4. Upward force principle
The principle of wing upward force produced is the same to the principle of the cylinder upward force[5,6]. As shown in Fig.4. Wing has a clockwise circulation movement, due to the wing move forward, fluid for the wing is for advection movement. Upper wing advection and circulation flow speed, pressure reducing, the lower part of the wing advection and circulation flow velocity decreases, and pressure. This is to create a lift force. Have flow resistance in the process of the flow at the same time, the wings have also been resistance.

\section{Surge}

Working condition of axial flow fan in unstable conditions, flow, pressure and current possible happens large fluctuations, flow occurs reciprocating flow, air and pipeline will have a strong vibration, noise significantly increase, this instability workers condition called surge $[7,8]$. The occurrence of surge would destroy the fan and pipeline equipment, threats the security of fan and the whole system. In the left side of axial flow fan performance curve has a saddle-shaped area, when the fan run in this segment, flow and pressure head and large ripple of power and other abnormal conditions sometimes will happen, namely surge, the working condition of unstable area known as the surge area. In fact, the surge is a phenomenon only unstable conditions that may be encountered, and in the area it is bound to appear unusual aerodynamic condition, such as flow separation or stall. These two kinds of abnormal condition are different, but they also have certain relations. Stall is a hydrodynamic phenomena caused by blade structure features, some of its basic characteristics, such as the rotating speed of stall area, the starting and vanishing points of the flow separation, etc., has its own rule, is not affected by the volume and shape of the fan system.

Surge is oscillation characteristics of fan performance and pipeline installation coupling effect, its basic features such as amplitude, frequency, dominated by the fan duct system volume, its power flow, pressure fluctuation is caused by unstable working condition of district, but experimental study show that the surge phenomenon always appeared with blade passage for air flow are closely related, and the increase of angle is related to the decrease of the flow[9]. Therefore, in the event of a surge of unstable operating area will appear flow separation.

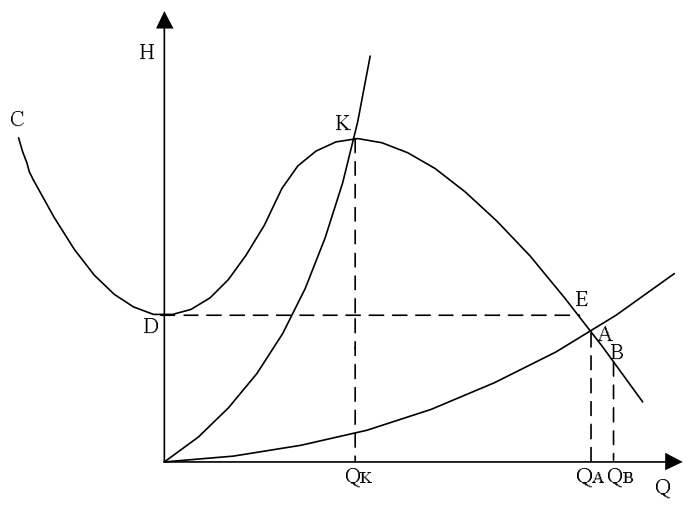

Figure 5. Q-H performance curve of axial flow fan

Fan in surge area work, flow volatility, generate flow, strong vibration in the fan, noise increases, and the wind constantly shake, the greater the capacity and head of fan, 
the greater the harm of the surge[10]. So the fan surge should meet the following conditions. Working point of the fan in has a hump shape Q-H performance curve of instability in the region. Air and Gas system has a large enough volume. It has to do with the fan to form an elastic aerodynamic system. The entire cycle of frequency and system flow oscillation frequency of step, produce resonance[11].

Q-H performance curve of axial flow fan is shown in Fig.5. $\mathrm{K}$ is the critical point, the right side of $\mathrm{K}$ point stable work area for the fan, the left unstable workspace.

\section{ACCIDENT ANALYSIS}

Taking a typical $300 \mathrm{MW}$ unit as an example, analyzes the surge accident after its SCR transformation. The unit is equipped with two axial flow adjustable PAF, fan model PAF19-14-2(P refers to primary air fan, A refers to axial flow fan, $F$ refers to blade adjustable, 19 refers to outer diameter, 14 refers to inside diameter), rated speed $1450 \mathrm{rpm}$, the motor rated power $1800 \mathrm{~kW}$. Boilers adopt low nitrogen burners transformation and increase of SCR De-NOx device. Air and gas system increased resistance $1000 \mathrm{~Pa}$ due to the installation of SCR devices.

\section{A. Accident equipment running status}

The first surge occurred in the process of the unit load down and stopping coal mill. When the accident occurred, the unit load was $220 \mathrm{MW}, \mathrm{B}, \mathrm{C}$ and D coal mill run, the total amount of coal was $97 \mathrm{t} / \mathrm{h}$. When mill A cold wind baffle was closed, PAF A outlet pressure rose to $8200 \mathrm{~Pa}$, current, air flow and air pressure had sharp fluctuations, the phenomenon of fan contend for wind occurred, duration was about $14 \mathrm{~min}$. The current of PAF A rapidly fell from 70A to 58A, PAF A did not contribute at this time, and the amplitude of PAF B parameters fluctuation was relatively small. During the surge occurred, the furnace pressure minimum to $-730 \mathrm{~Pa}$, with oil supporting to obtain stable combustion, the minimum load was 180MW.

When the second surge occurred, the unit load was 220MW, coal mill B, C and D run. The current of PAF A rapidly fell from $70 \mathrm{~A}$ to $60 \mathrm{~A}$, current, air flow and air pressure had sharp fluctuations, the phenomenon of fan contend for wind occurred, duration was about $2 \mathrm{~min}$, the furnace pressure minimum to $-440 \mathrm{~Pa}$, with oil supporting to obtain stable combustion. Before the surge occurred, the opening of cold air port of PAF was $6 \%$ below. The opening of the hot air port was generally more than $80 \%$. The main parameters before two surge accidents are shown in Table I. In addition, under normal operating conditions, the parameters such as flow, current and pressure of PAF A fluctuations were less than PAF $B$. The current fluctuation of PAF A was about 2-4A, the flow fluctuation about $10 \mathrm{~km} 3 / \mathrm{h}$, pressure fluctuation about $100 \mathrm{~Pa}$. The parameters of PAF B were relatively stable.

\section{B. Brief analysis of reasons}

The fan performance cure is shown in Fig.6. Near the stall line is unstable region, easy to produce surge or stall, operating point near the stall line prone to stall. Due to the operation mode, mill switching, coal change, fan itself and other factors, PAF are in a high pressure head, low flow operation condition, sometimes it will lead to surge.

The SCR devices have high air resistance, high fan

TABLE I. THE MAIN PARAMETERS BEFORE TWO SURGE ACCIDENTS

\begin{tabular}{|c|c|c|c|c|c|c|c|c|c|}
\hline No. & $\begin{array}{c}\text { A } \\
\text { current }\end{array}$ & $\begin{array}{c}\text { B } \\
\text { current }\end{array}$ & $\begin{array}{c}\text { A } \\
\text { Open }\end{array}$ & $\begin{array}{c}\text { B } \\
\text { Open }\end{array}$ & $\begin{array}{c}\text { A } \\
\text { Flow }\end{array}$ & $\begin{array}{c}\text { B } \\
\text { Flow }\end{array}$ & $\begin{array}{c}\text { A Air } \\
\text { Pressure }\end{array}$ & $\begin{array}{c}\text { B Air } \\
\text { Pressure }\end{array}$ & $\begin{array}{c}\text { Main-piping } \\
\text { Pressure }\end{array}$ \\
\hline & $A$ & $A$ & $\%$ & $\%$ & $\mathrm{~km}^{3} / \mathrm{h}$ & $\mathrm{km}^{3} / \mathrm{h}$ & $k P a$ & $k P a$ & $k P a$ \\
\hline 1 & 70.2 & 69.8 & 46 & 41 & 183 & 174 & 8064 & 8104 & 6.32 \\
\hline 2 & 70 & 67 & 46 & 40 & 162 & 158 & 7995 & 8104 & 6.12 \\
\hline
\end{tabular}

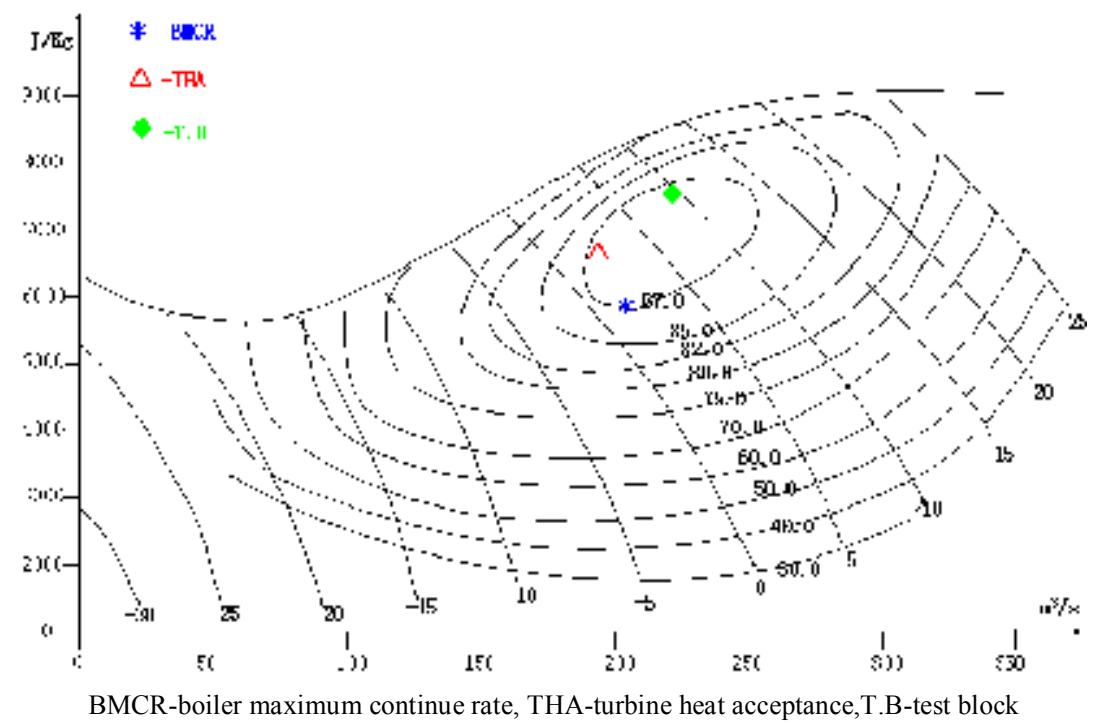

Figure 6. Fan performance curve 
pressure head and fan has much noise to environment and are apt to break down with vibration. The two surges occurred in low or middle load, high wind pressure and low air flow working condition. At this point, PAF pressure is high, air flow is small, according to exit static pressure approximate estimates for the fan total pressure, these two points are near the stall line area, such as to mill switch is easy to induce surge.

TABLE II. EXPERIMENTAL DATA OF DIFFERENT COAL QUALITY

\begin{tabular}{|c|c|c|c|}
\hline No. & $\begin{array}{c}\text { Gain } \\
\text { K }\end{array}$ & $\begin{array}{c}\text { Inertia time } \\
\boldsymbol{\theta}\end{array}$ & $\begin{array}{c}\text { Pure lag time } \\
\boldsymbol{\tau}\end{array}$ \\
\hline 1 & 0.0127 & 796.6 & 32 \\
\hline 2 & 0.0128 & 517.4 & 32 \\
\hline 3 & 0.0112 & 496.7 & 32 \\
\hline 4 & 0.0113 & 729.4 & 32 \\
\hline 5 & 0.0115 & 634.1 & 32 \\
\hline
\end{tabular}

The changes of coal quality tend to cause surge, such as coal moisture increase leads to insufficient drying time, was forced to open the hot wind, close the cold wind, too much air flow through the preheater, and is bound to increase the primary air system resistance. In order to maintain primary air pipe pressure, it is necessary to increase the PAF outlet pressure. When the PAF operate under high pressure head and low flow, it is easily to into the unstable region and leads to surge. Select the conditions under different experimental coal quality, data is shown in Table 2. As can be seen from the comparison of the calculated multiple sets of transfer function, gain and inertia time have greatly different, reflects the change of controlled object characteristics, will inevitably result in changes in the air and gas systems.

Analysis of the two PAF parameter differences may be related to the duct system resistance characteristics (such as export baffle opening inconsistent), air pressure measurement error, the zero of the two stage blade, blade angle displacement, the synchronized opening of the blade, idle travel produced by wear, idle running of regulating mechanism and so on.

\section{MEASURES TAKEN}

Discussed above two were is the model of parallel running of fan operating situation, fan performance and the pipeline resistance characteristic is symmetric, the accident after the working point is symmetrical, it is good for operation adjustment.

To prevent axial flow fan working point at run time in rotating stall and surge area, should be careful in choosing fan often working point to verify whether fell on the stability zone. At the same time, when choosing adjustment method attention, should note the changes of the working point. Results show that, as long as the moving blade angle difference of the two blowers or kept within critical bounds, no surging of the blowers will occur.

\section{A. Adjustment of PAF operation}

Check the zero of two PAFs rotor blade are consistent, check the opening of rotor blade if there is a difference, check whether there is any displacement on the rotor angle, check and minimize or eliminate the idle motion of driving mechanism, reduce the parameters fluctuation, maintain two PAFs current basic consistent, as far as possible to maintain two PAFS outlet pressure balance. Ensure that Fig. 1 contact pipe during normal operation is almost no flow. So, it do not provide the required air volume of fan surge.

\section{B. Adjustment of coal pulverizing system}

Coal pulverizing system is one of main components in power plant, and its states that superior character, scientific system optimization and suitable operation, is crucial to the safe and economic operation for a power plant. When actual operation of coal pulverizing system meet the requirements, could be considered appropriate to reduce the mill outlet temperature, in order to reduce the amount of hot air, reducing PAF outlet pressure. The operator at the time of start and stop pulverizing system, hot and cold air damper operation should be carried out slowly and closely monitor the hot primary flow pressure and PAF outlet pressure, as far as to avoid fan outlet pressure jump problem.

\section{Integral adjustment of air and gas system}

Depending on the load segment, the primary air pipe pressure dynamic adjustment, try to prevent low flow and high pressure situation. Appropriate to increase the sootblowing number of air preheater and SCR to reduce air preheater and SCR resistance and reduce the system resistance.

\section{CONCLUSIONS}

Due to changes in the resistance of air and gas systems after the denitration system transformation, so that the whole system aerodynamic field changes, it is easily to cause surge accidents. By analyzing the large axial flow adjustable fan PAF surge accident of the thermal unit, the anti-surge control measures are formulated, provides reference to reduce the occurrence of surge accidents.

\section{REFERENCES}

[1] An Liansuo, Pumps and fans, Beijing:China Electric Power Press, 2008.

[2] Liu Jiayu, The retrofitting and reliability analysis on power station fans, Beijing:China Electric Power Press, 2002.

[3] Ding Peng, Wu Yuedong, "Analysis on stall and surge of variable blade adjustable axial flow fan and improvement measures", Fan Technology, vol. 3, pp.66-69, 2007.

[4] Ye Xuemin, Li Jun, Wang Songling, et al. "Aerodynamics of adjustable blade axial fan under abnormal installation angles", Proceedings of the CSEE, vol. 29(26), pp.79-84, 2009.

[5] Zhu Xiaocheng, Lin Wanlai, Du Zhaohui, "Experimental and numerical investigation of the flow field in the tip region of an axial ventilation fan", Journal of Fluid Engineering", vol. 127(3), pp.299-307, 2005.

[6] Li chunhong, "Analysis of the stall and surge of axial-flow fans", Thermal Power Generation, vol. 3, pp.76-78, 2008.

[7] Hua guojun, "Analysis of the stall and surge of axial-flow fans", Zhejiang Electric Power, vol. 2, pp.40-43, 2002.

[8] Chang zezhou, etc. Practical technology of axial flow fan, Beijing:China Mechine Press, 2005.

[9] Liu jiayu, The retrofitting and reliability analysis on power station, Beijing:China Electric Power Press, 2002.

[10] Lu Zhihou, "The technical innovation of fans and cold air tube system in NO.8 boiler of Huangtai power station", Power Station Auxiliary Equipment, vol. 2, pp.19-26, 1999.

[11] Wang Jun, Wu Guanghui, Wu Keqi, "The research of performance test and inflow-simulation for single-double runner fan", Journal of Engineering Thermophysics, vol. 25(4), pp. 600-602, 2004. 